\title{
Clinical and regulatory protocol for the treatment of jaundice in adults and elderly subjects: A support for the health care network and regulatory system ${ }^{1}$
}

\author{
Protocolo clínico e de regulação para o tratamento de icterícia no adulto e idoso: \\ Subsídio para as redes assistenciais e o complexo regulador
}

\author{
José Sebastião dos Santos ${ }^{\mathrm{I}}$, Rafael Kemp ${ }^{\mathrm{II}}$, Ajith Kumar Sankarankutty ${ }^{\mathrm{III}}$, Wilson Salgado Júnior ${ }^{\mathrm{IV}}$, Fernanda \\ Fernandes Souza ${ }^{\text {, }}$ Andreza Correa Teixeira ${ }^{\text {II }}$, Guilherme Viana Rosa ${ }^{\text {VII }}$, Orlando Castro-e-Silva ${ }^{\text {III }}$ \\ I PhD, Professor, Division of Digestive Surgery, Department of Surgery and Anatomy, Ribeirão Preto Faculty of Medicine, Univesity of \\ São Paulo, Brazil. \\ II MD, Assistant, Division of Digestive Surgery, Department of Surgery and Anatomy, Ribeirão Preto Faculty of Medicine, University of \\ São Paulo, Brazil. \\ III PhD, Professor, Division of Digestive Surgery, Department of Surgery and Anatomy, Ribeirão Preto Faculty of Medicine, University of \\ São Paulo, Brazil. \\ Iv MD, Professor, Division of Digestive Surgery, Department of Surgery and Anatomy, Ribeirão Preto Faculty of Medicine, University of \\ São Paulo, Brazil. \\ $\checkmark$ Fellow Master degree, Member of the Liver Transplant Program of the Division of Digestive Surgery, Department of Surgery and \\ Anatomy, Ribeirão Preto Faculty of Medicine, University of São Paulo, Brazil. \\ ${ }^{\text {v }}$ Fellow Master degree, Member of the Liver Transplant Program of the Division of Digestive Surgery, Department of Surgery and \\ Anatomy, Ribeirão Preto Faculty of Medicine, University of São Paulo, Brazil. \\ VII MD. Resident, Department of Surgery and Anatomy, Ribeirão Preto Faculty of Medicine, University of São Paulo, Brazil. Brazil.

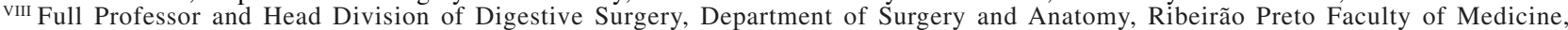 \\ University of São Paulo, Brazil.
}

\begin{abstract}
Purpose: Clinical interventions and controlled access to the health care system can be improved by a Regulatory System (RS) and Clinical and Regulatory Protocols (CRPs). The objective of the present paper is to present the methodology used for elaborating the CRPs. Methods: The process used to elaborate the CPRs involved a scientific co-operation between university and health care system. Workshops were held and attended by primary care practitioners, RS team, and matrix team (university specialists supporting primary care practitioners). Results: The treatment of jaundice in adults and elderly subjects is amongst the themes selected for elaborating the CRPs since jaundice is a medical sign frequently seen in four clinical scenarios involving distinctive diagnostic and therapeutic interventions which can be performed in different health care settings. Evaluation guidelines as well as the clinical and regulatory procedures were established for different health care settings. The most relevant clinical and regulatory interventions were expressed as algorithms in order to facilitate the use of CRPs by health care practitioners. Conclusion: It is expected that the implementation of this protocol will minimise the imbalance between the icteric patients' needs and the treatment modalities being offered, thus contributing to a more co-operative health care network.
\end{abstract}

Key words: Clinical and Regulatory Protocols. Guidelines. Regulatory Systems. Medical Regulation. Jaundice. Unified Health System

\section{RESUMO}

Objetivo: As ações clínicas e de ordenação do acesso à rede de saúde podem ser aperfeiçoadas pelo Complexo Regulador (CR) e pelos Protocolos Clínicos e de Regulação (PCR). Nesse trabalho apresenta-se a metodologia de elaboração dos PCR mediante cooperação entre universidade e sistema de saúde. Métodos: O processo utilizado para a elaboração dos PCR envolve oficinas com a participação de profissionais da atenção básica, do CR e das equipes matriciais (especialistas da universidade que dão suporte às equipes de atenção básica). Resultados: Dentre os temas selecionados para elaboração dos PCR, incluiu-se a icterícia no adulto e no idoso. Trata-se de um sinal clínico que comporta quatro cenários de apresentação com distintos percursos diagnósticos e terapêuticos passíveis de serem executados em diferentes pontos da rede assistencial. As diretrizes de avaliação, bem como as decisões e ações clínicas e reguladoras cabíveis para os diferentes cenários foram estabelecidas desde a atenção básica até o hospital terciário. As ações clínicas e reguladoras mais relevantes foram colocadas em algoritmo para facilitar o emprego do protocolo pelos profissionais de saúde. Conclusão: Há a expectativa que a implementação desse protocolo possa minimizar o descompasso entre as necessidades dos pacientes ictéricos e a modalidade de serviço oferecida e, assim, contribuir para a configuração de uma rede assistencial mais cooperativa.

Descritores: Protocolo Clínico e de Regulação. Regulação Médica. Icterícia. Sistema Único de Saúde.

1. Work performed in the Division of Digestive Surgery of the Department of Surgery and Anatomy, Ribeirão Preto Faculty of Medicine, University of São Paulo, Brazil. 


\section{Introduction}

The Unified Health System (SUS) was established in Brazil in 1988, and among other principles and guidelines, has the objective of decentralising the health care interventions and configuring an increasingly hierarchically complex health care network based on primary health care. ${ }^{1}$

The analysis of the concepts, operational norms, guidelines, and agreements reinforces the roles of primary care, which includes the attribution of performing clinical interventions regarding the most prevalent health problems and co-ordination to assure access to health services. ${ }^{2-4}$

Although the SUS implementation has amplified the primary health care structure, both organisation and performance regarding clinical interventions as well as coordination of the access to other health services are still inefficient. According to the Ribeirão Preto Municipal Health Secretary (MHS), in 2004 there were 293 primary care physicians who could provide 928,224 consultations and meet $91 \%$ of the medical needs of the population. However, these practitioners provided 586,528 consultations and met $57.43 \%$ of these medical needs. ${ }^{5}$

The expected consultation ratios for different health care services were the following: $63 \%$ for primary care, $22 \%$ for specialised care, and $15 \%$ for emergency care. ${ }^{6}$ Based on the total number of consultations, the primary care rate was $35.6 \%$ compared to $34.15 \%$ and $30.29 \%$ for specialised and emergency care services, respectively. ${ }^{5}$

Inefficient clinical interventions and poor primary care co-ordination have resulted in excessive demand for specialised and emergency care services. Amongst the measures adopted by the Municipal Health Secretary in 2005, we may cite the implementation of the Regulatory System (RS) for health care demand. ${ }^{5}$ The RS is aimed at mapping the resources regarding the health care services offered by the city of Ribeirão Preto and at structuring the various regulatory units concerning inpatient and outpatient beds, moderately and highly complex medical exams, medical consultations, pharmaceutical care, sanitary and epidemiological surveillance, emergency care and patient removal, audit and assessment, all in an integrated way.

Health problems not deserving primary care coverage and not characterised as being emergency are referred to the RS team by means of referral orders, which are analysed so that the optimal action can be taken according to the resources available in the health care network. Such a process also shows the deficiencies in the health care network, thus helping administrators make appropriate investment decisions in terms of health care. The different RS units, particularly the emergency one, can also be used by medical teams or users by telephone, internet and fax. This regulatory process consists of technical and management knowledge so that the best response can be provided for a given need.,

Therefore, clinical attention and co-ordinated health care access provided by the different SUS health care services can be defined by the RS. On the other hand, consensus on clinical possibilities and available health care access based on the local sanitary situation and scientific evidence $^{8}$ should exist among the practitioners working in different medical units.

The Ministry of Health and National Council of Health Secretaries have adopted the term 'Clinical and Regulatory Protocols' (CRP) ${ }^{3}$ for systematic orientations and practical results based on scientific evidence ${ }^{8}$ thus helping users, health care practitioners, and administrators make clinical and regulatory decisions about a given health issue. The steps for elaborating such CRPs involve selection of themes, synthesis of the evidence, formulation of recommendations, dissemination and implementation, review and up-dating, and finally, validation by experts, practitioners, users, and managers. ${ }^{8}$

In order to improve the local primary health care, two research projects are being currently developed by the University of São Paulo (USP) in co-operation with the Ribeirão Preto Municipal Health Secretary and financially supported by the Waldemar Barnsley Pessoa Foundation. These objective of these research projects is to strengthen the link between specialised and primary care practitioners as well as to implement the RS. Clinical and regulatory protocols are one of the results most expected by the community.

The objective of the present paper to present a methodology for elaborating clinical and regulatory protocols through scientific co-operation between university and health care system based on the model proposed for the treatment of jaundice in adults and elderly subjects.

\section{Methods \\ Selection of Themes for Elaborating Clinical and Regulatory Protocols}

The list of themes for elaborating CRPs is based on either "mixed" or "authentic" health problems seen in the health care system and whose solution implies the contingent use of different elements from the health care network and other social resources. Therefore, abdominal pain due to acute appendicitis is an authentic health problem that may be a theme for CRP, since the patient can be referred to a moderate-high complexity hospital depending on his or her health condition, which includes risks inherent to surgery and anaesthesia. On the other hand, domestic violence against women, children, or the elderly are considered mixed health problems since they can be clinically and psychologically resolved by primary care or specialised practitioners. However, these mixed health problems should also be regulated by other services regarding citizenship and justice.

The themes are analysed and selected by primary care practitioners, matrix care teams, and an RS team. A matrix care team is formed by specialised health practitioners linked to the University of São Paulo who support primary care practitioners either in person or on-line. The themes representing the most prevalent problems seen in the health care network are chosen by professionals from MHS and USP through workshops. Each theme is elaborated by one 
professional, preferably linked to the university, with participation of primary care practitioners and the RS team.

Guidelines for Elaborating the Clinical and Regulatory Protocols

These CRPs should define the clinical dimension for each theme regarding the different elements of the health care network and also explain the reasons why elective and emergency specialised services, moderately and highly complex medical exams, hospitalisation, and high-cost pharmacological aid should be provided. The protocol format should contain a brief introduction of the theme, including clinical and laboratory findings setting limits for each health care service. Flowcharts representing the most relevant clinical and regulatory interventions, including hyperlinks, will facilitate the use of the protocol by health care practitioners. Relevant observations can be attached along with the bibliographic references. The guidelines used in the CRPs should be based on scientific evidence, always emphasising the recommendations stated by the World Health Organisation and Pan American Health Organisation, the systematic reviews produced by the Brazilian Cochrane Centre, and the PubMed citations.

CRPs may be elaborated by the matrix care team or other professionals with scientific, clinical, and administrative knowledge under the supervision of a technical group designated to follow up execution and methodology. The protocol content must reproduce the multidisciplinary and multiprofessional interventions taken to handle health-related problems and also be in tune with the public health policies and local health care network. Therefore, a CRP for an obese patient with backache, for example, should begin with initial attention to a series of measures agreed upon by family physician, orthopaedist, nurse, pharmacist, physical therapist, and nutritionist. If necessary, other health care services may be ordered through the same regulatory process.

The rationale for guiding the access to health care services is based on the primary care door, both in terms of elective needs and referral to other health providers. 2,3 Specialised evaluations should be structured before being sent to the RS team. ${ }^{5}$ Low-complexity emergency needs can be addressed at the primary care level, including chronic cases that are being followed up and become acute, whereas the more severe cases should be referred to the emergency medical centre according to the regulatory requirements. ${ }^{5,7}$

The technical and regulatory components of the CRPs reflect the interaction of services (hospitals, health care units, ambulances) available in the community (i.e. Ribeirão Preto) considering professional capacity, technology, preventive and curative products, outpatient and inpatient settings, list of medicines, pathological and image exams, and number of inpatient beds, including the observation ones.

Clinically, CRPs are based on health problems such as signs (neck lump, bruised finger, blood in the urine, jaundice), symptoms (palpitation, chronic cough, chest pain, abdominal pain, toothache), or the disease itself (hypertension, diabetes mellitus, arthrosis). With regard to the preventive measures, CRPs take into account the recommendations adopted by the surveillance services as well as clinical and laboratory investigation for screening the most prevalent diseases according to age and gender.

Orientations for Validating, Disseminating, and Revising the CRPs

The CRPs are sent to primary care practitioners and to the RS team for evaluation and suggestions, which are then recorded and annexed. The initial suggestions are presented at validation workshops attended by members of the matrix care teams, RS team, university practitioners, and health care providers linked to SUS. Once validated, the CRPs are organised into textbook and media material for extensive distribution among all health care practitioners. The CRP revision is promoted by universities linked to the MHS and services are provided by the MHS itself.

\section{Results}

Based on MHS administrative planning and USP research goals, a CRP for treatment of jaundice in adults and the elderly was elaborated according to methodology proposed and presented as follows.

\section{Clinical and Regulatory Protocol for Obstructive Jaundice in Adults and Elderly Subjects}

\section{Introduction and Reasons}

In most cases, jaundice patients seeking health care may presentfour distinctive clinical scenarios. Patients with asymptomatic jaundice (i.e. absence of fever and pain) and clinically stable can have their evaluation and treatment scheduled. Patients with a palpable gall bladder may present periampullary neoplasia and should be referred to a tertiary hospital for digestive surgery, whereas the other patients should be submitted to biochemical and image exams to determine whether the disease is to be clinically or surgically addressed..$^{9110}$ On the other hand, jaundice with pain and fever without neurological and cardiorespiratory involvement characterises a case of moderate emergency to be evaluated and treated by services of moderate complexity, whereas the more severe cases of mental confusion and hypotension require clinical stabilisation, removal, and tertiary hospitalisation. Jaundice implies different syndromic, anatomical, and etiological diagnoses whose treatment may involve different health care settings and time, thus justifying the CRP elaboration. ${ }^{11,12}$

\section{Theoretical Considerations}

Jaundice is a clinical sign characterised by yellow skin, mucosa, and sclera resulting from an increased production of bilirubin, usually over 2.5 and $3.0 \mathrm{mg} / \mathrm{dl}$. Bilirubin is produced by the degradation of complex proteins, mainly haemoglobin, and is then metabolised in the liver by hepatocytes in a process called capture. The 
non-conjugated bilirubin (indirect form) is conjugated within the hepatocytes, becoming more polarised and watersoluble (direct bilirubin). As a result, the conjugated bilirubin can be excreted through the biliary ducts. ${ }^{13}$

Therefore, hyperbilirubinemia and jaundice may occur by means of two mechanisms:

I - Increased production of bilirubin: haemolysis, formation of vulnerable red cells (thalassemia, anaemia), haematoma resorption, transfusion;

II - Decreased depuration of bilirubin

A - Hereditary defects: Dubin-Johnson's and

Rotor's syndromes

B - Cholestasis:

1 - Hepatocellular injury: hepatitis (viral, drug-related), pregnancy, and sepsis.

2 - Biliary obstruction: biliary lithiasis, periampullary neoplasia, pancreatitis.

On the basis of the physiological role of bilirubin and the determinants of its increase, jaundice can be defined as follows. ${ }^{13}$

- Pre-hepatic (production or capture)

- Hepatic (capture, conjugation and excretion)

- Post-hepatic (biliary flow)
Cholestasis is a condition in which bile cannot reach the duodenum due to problems related to hepatocyte excretion or obstruction of the flow between hepatocytes and ampulla of Vater. Infectious contamination by stagnated bile and inflammation of the biliary ducts characterise cholangitis. ${ }^{13-}$ 16

\section{Primary Care Approach to Jaundicein Adults and}

Elderly Subjects

- Differentiation of pre-hepatic and hepatic jaundice from the post-hepatic one

- Differentiation of mild inflammatory pictures (acute hepatitis, mild pancreatitis, and mild cholangitis) from severe ones (severe pancreatitis, severe cholangitis, and severe acute liver failure).

In the majority of cases this differentiation can be done through anamnesis and clinical examination, in addition to some other auxiliary exams available in all health care services. ${ }^{17}$ This process allows patients to be etiologically diagnosed and optimally treated. The icteric patient seeking health care usually belongs to one of the following four scenarios (Figure 1):

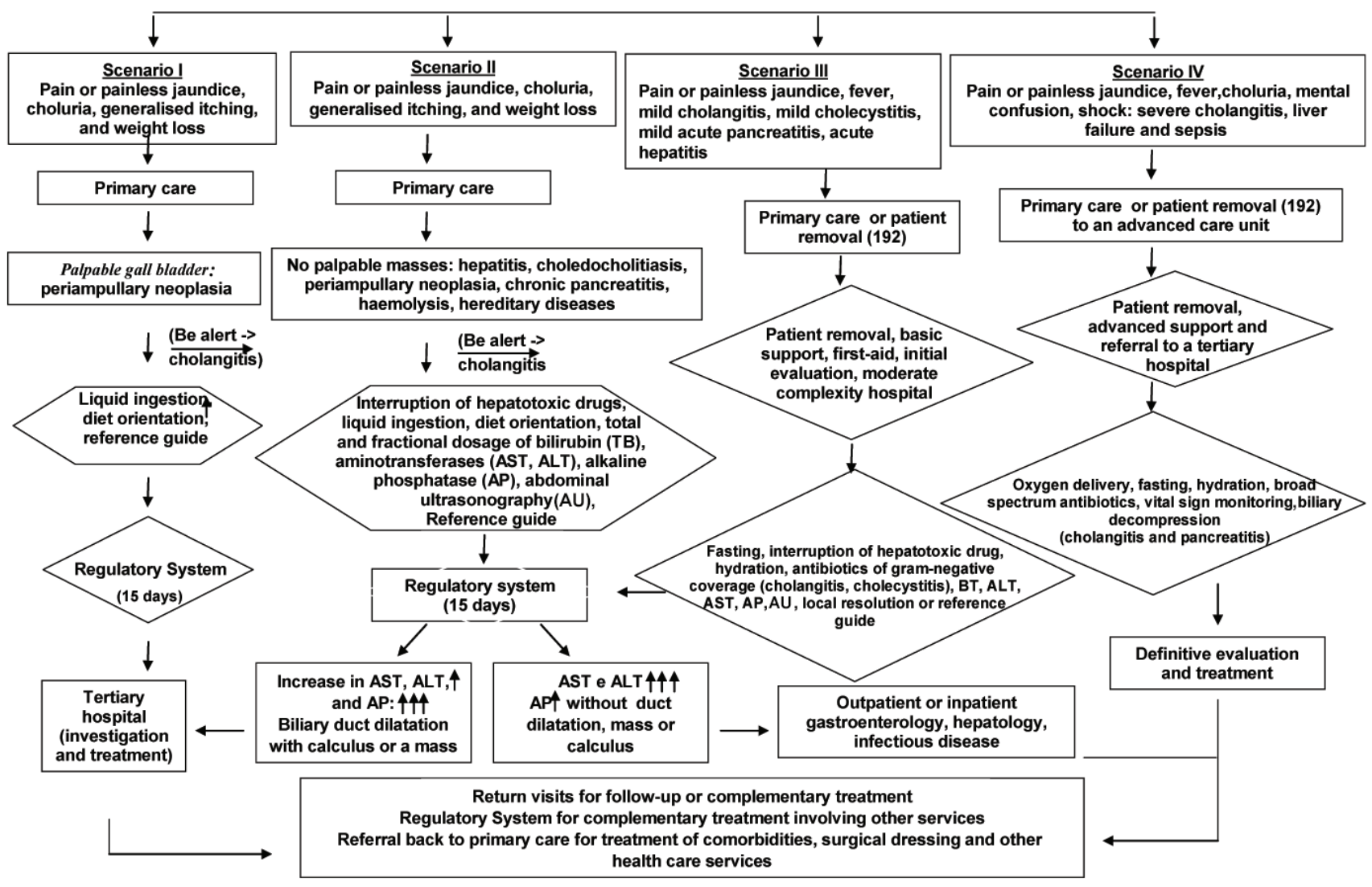

FIGURE 1 - Clinical and regulatory protocol of jaundice in adults and elderly subjects. 
Scenario I

Clinical presentation

- Painless jaundice, usually progressive, choluria, faecal acholia, generalised itching, and weight loss.

- $\quad$ Palpable vesicle (Courvoisier-Terrier sign).

\section{Syndromic and Etiological Diagnosis}

- Extra-hepatic cholestasis, probably secondary to a periampullary tumour. ${ }^{13,17}$

\section{Clinical and Regulatory Measures}

- Increased ingestion of fluids to maintain a minimum urinary loss of $0.5 \mathrm{ml} / \mathrm{kg} / \mathrm{h}$ (to prevent renal failure).

- Low-fat diet (to minimise the discomfort caused by fat ingestion and diarrhoea).

- $\quad$ itching control: ( $1^{\text {st }}$ line $)$ - Dexchlorpheniramine (4-16 mg a day in 2-4 divided doses); Hydroxyzine $(25 \mathrm{mg}, 3$ times a day); Cholestyramine (4-6g, 2 times a day and 30 min prior to meals, not to be taken concomitantly with other medications $) ;\left(2^{\text {nd }}\right.$ line) - ursodeoxycolic acid (13-15 mg/kg a day divided into 2-3 doses after meals); Naltrexone (50 mg/day). ${ }^{13,18}$

- The primary care physician fills out the referral order manually or electronically and sends it to the RS unit.

- The primary care physician alerts the patient to the possibility of cholangitis (a rare event): should this occur, the patient must seek a health care unit or an emergency inpatient unit. If the patient is not able to do so, he or she must use the 192 emergency telephone network.

- The RS agent analyses the referral order and schedules the medical care in a tertiary hospital within 15 days.

- The patient can be informed about the date, time, and place as follows:

- $\quad$ by telephone (RS agent or primary care unit)

- $\quad$ by the community health worker

- Return visits or complementary treatments involving a tertiary hospital should be scheduled by its administrative staff.

- The tertiary hospital team should refer the patient back to the primary care unit and describe the treatment performed, including possible complementary treatments. Other comorbidities or treatment problems can be handled by the primary care practitioners, such as surgical wound dressings, mild pain management, and so on.

- Any other complementary treatment beyond the scope of primary or tertiary care should be requested by means of a referral order to the RS team.

Complementary diagnostic and therapeutic investigations should be requested by the primary care physician by means of RS referral because the clinical evidence indicates cancer of the periampullary region (see Scenario I). In this case, the patient will be submitted to image and tumour markers examinations such as: digestive endoscopy, tomography, nuclear magnetic resonance and, possibly, endoscopic ultrasonography with a biopsy. Moreover, the jaundice treatment may require biliary and digestive decompression via endoscopy or even major surgery; hence the demand for specialised practitioners and infrastructure. ${ }^{9}$

Communication between the various units of the health care network should be the responsibility of primary care practitioners and the RS team, and not of the user, in order to assure full and effective health care for the patient. Therefore, there is no reason to refer an icteric patient presenting with a palpable gall bladder to be submitted to clinical and image exams only. In this case, both patient and health care system have disadvantages. The former has his or her treatment delayed because the same exams would have to be repeated in the tertiary hospital due to the inherent pathological changes and condition of the patient, and the latter would have to invest more resources.

It should also be emphasised that the users should not have to go to different health care units in order to make new appointments and undergo exams and procedures. Access to full treatment care must be assured by the regulatory system and health care services, and the patients must be informed of the date, time, and place of their appointments. Because of the technology currently available, it is unacceptable that users leave the health care units carrying consultation, exam, or procedure orders without even having access to treatment.

The access to health care services is not unidirectional. Once the health problem has been resolved, the patient should be referred back to the primary care unit so that other possible comorbidities or treatment-related problems can be addressed, such as surgical wound dressings and instructions about pain and nutritional management. If other complementary treatments beyond the scope of primary and tertiary care are required, then referral orders should be sent to the RS unit manually or electronically.

\section{Scenario II}

\section{Clinical presentation}

- Pain or painless jaundice associated or not with:

- choluria, faecal acholia, anorexia, weight loss

- alcohol ingestion, use of medications or hepatotoxic drugs

- $\quad$ previous history of abdominal or biliary surgery

- history of blood transfusion

- $\quad$ signs of hepatopathy (palmar erythema, ascites, gynecomastia, testicular atrophy, 
vascular spiders, and collateral circulation).

- hepatosplenomegaly

\section{Syndromic Diagnosis}

- Differentiation of pre-hepatic and hepatic jaundice from the post-hepatic one.

\section{Probable Etiological Diagnoses}

- Pre-hepatic causes: excessive haemolysis (spherocytosis), ineffective erythropoiesis (thalassemia), and resorption of extensive haematomas.

- Hepatic causes:

- Increase in non-conjugated bilirubin: Gilbert's syndrome, Crigler Najar syndrome, use of drugs (Rifampicin)

- Increase in conjugated bilirubin (intrahepatic cholestasis):

- $\quad$ viral hepatitis, alcohol-related hepatitis, autoimmune hepatitis drug-related hepatitis (acetaminophen, penicillin, oral contraceptives, non- steroid antiinflammatory drugs, tricyclic antidepressives) hereditary diseases (haemochromatosis, Wilson's disease, Dubin-Johnson's syndrome, Rotor's syndrome) systemic diseases (sarcoidosis, amyloidosis, tuberculosis, glycogen storage disease, celiac disease) others (sepsis, prolonged parenteral nutrition, pregnancy)

- Post-hepatic Causes (extra-hepatic cholestasis)

- Increase in conjugated bilirubin:

- $\quad$ intrinsic obstruction (calculus, traumatic biliary injuries, parasites, cholangiocarcinoma, vesicular cancer, cryptosporidium in AIDS patients) extrinsic obstruction (acute and chronic pancreatitis, pseudocyst, cancer of pancreas and duodenum). ${ }^{13,16,17}$

\section{Clinical and Regulatory Measures}

- Increased ingestion of fluids for keeping diuresis above $0.5 \mathrm{ml} / \mathrm{kg} / \mathrm{h}$ (to prevent renal failure).

- Low-fat diet (to minimise the discomfort caused by fat ingestion and diarrhoea).

- Interruption of drugs causing cholestasis.

- $\quad$ itching control: ( $1^{\text {st }}$ line $)$ - Dexchlorpheniramine (4-16 $\mathrm{mg}$ a day in 2-4 divided doses); Hydroxyzine (25mg, 3 times a day); Cholestyramine (4-6 g, 2 times a day and 30 min prior to meals, not to be taken concomitantly with other medications $) ;\left(2^{\text {nd }}\right.$ line) - ursodesoxycolic acid (13-15 mg/kg a day in 2-3 divided doses after meals); Naltrexone (50 mg/day). ${ }^{13,18}$

- The primary care physician orders a blood count with reticulocytes, total and fractional serum bilirubin levels (conjugated and nonconjugated), aminotransferases (aspartate aminotransferase and alanine aminotransferase,AST and ALT, respectively,), alkaline phosphatase (ALP), prothrombin time (PT), and abdominal ultrasonography. ${ }^{16,19}$

- The primary care physician sends to the RS team a referral order containing clinical information, laboratory exam results, and image exams.

- The primary care physician alerts the patient to the possibility of pain and fever; should this occur, the patient must seek a health care unit or an emergency inpatient unit. If the patient is not able to do so, he or she must use the 192 emergency telephone network.

- $\quad$ Based on the information received, the RS team can differentiate pre-hepatic jaundice and intra-hepatic cholestasis from extra-hepatic cholestasis. In extra-hepatic cholestasis, alkaline phosphatase is predominantly increased compared to aminotransferase, and abdominal ultrasonography shows dilated biliary ducts. ${ }^{13,16,19}$

- The RS physician must schedule clinical gastroenterology or hepatology services for cases of pre-hepatic jaundice and intra-hepatic cholestasis, whereas the cases of extra-hepatic cholestasis are referred to surgical gastroenterology within 15 days.

- The patient can be informed about the date, time, and place as follows:

- $\quad$ by telephone (RS or primary care team)

- by a community health worker

- Return visits or complementary treatments involving a tertiary hospital should be scheduled by its administrative staff.

- The tertiary hospital team should refer the patient back to the primary care unit and describe the treatment performed, including possible complementary treatments. Other comorbidities or treatment problems can be handled by the primary care practitioners, such as surgical wound dressings, mild pain management, and so on.

- Any other complementary treatment beyond the scope of primary or tertiary care should be requested by means of a referral order manually or electronically filled out.

Clinical evaluation and routine exams, such as blood count, total and fractional serum bilirubin levels (conjugated and non-conjugated), aminotransferases (aspartate aminotransferase and alanine aminotransferase, respectively, AST and ALT), alkaline phosphatase, 
prothrombin time, and abdominal ultrasonography, all may be ordered by the primary care physician to distinguish non-obstructive jaundice (clinical approach) from obstructive jaundice (surgical approach) in almost $75 \%$ of the cases. ${ }^{16}$

In the intra-hepatic cholestasis due to toxic or ischemic injury, the aminotransferase level is generally ten times higher than the maximum values, whereas the bilirubin levels are only five times higher. In both intra-hepatic cholestasis due to viral or alcohol-related hepatitis and acute biliary obstruction, on the other hand, aminotransferase and bilirubin levels are, respectively, 5 and 10 times higher than their maximum values. Sometimes, the aminotransferase levels exceed the 10-time limit in the cases of viral hepatitis, whereas bilirubin levels can also exceed such a limit in cases of acute biliary obstruction and alcohol-related hepatitis. Therefore, the RS team can refer the cases more adequately to specialised treatments based on the information obtained from such a differentiation, thus maximising the patient's time and saving health care resources. ${ }^{16,19}$

The cases of pre-hepatic jaundice and intra-hepatic cholestasis should be referred to health care units where clinical support exists, including viral hepatitis tests, diagnostic markers for autoimmune diseases (protein electrophoresis and determination of immunoglobulin and anti-mitochondrial, anti-smooth muscle, and anti-nucleus antibodies), and for metabolic disorders (urinary copper excretion, ceruloplasmin, alpha-1 antitrypsin, and iron biochemistry, among others). On the other hand, patients with extra-hepatic cholestasis require specialised health care centres possessing image resources and practitioners experienced in invasive endoscopy and radiology as well as major surgeries. Also, chronic cholestasis may result in cirrhosis, which would require a liver transplantation. In this case, the patient must be referred to a highly specialised centre with multidisciplinary and multiprofessional health teams. ${ }^{13,16,17,19}$

\section{Scenario III}

\section{Clinical Evaluation}

- Pain or painless jaundice and fever associated or not with:

- $\quad$ history of biliary pain or biliary surgery

- history of alcohol ingestion, use of medications or hepatotoxic drugs

Differential Diagnosis

- Mild cholangitis

- Acute hepatitis

- Acute cholecystitis

- Acute pancreatitis

- Hepatic abscess

- Pyelonephritis

\section{Clinical and Regulatory Measures}

- Fasting; hydration and fluid replacement by intravenous access in order to keep urinary loss above $0.5 \mathrm{ml} / \mathrm{kg} / \mathrm{h}$.

- Prescription of antithermic medications.
- Contact with emergency medical regulation (telephone number 192).

- If the patient has to be removed, the emergency medical regulation should send a mobile basic unit.

- If diagnosis is uncertain, the patient should be referred to an emergency outpatient service (first-aid unit) or a moderate complexity hospital.

- Any other complementary diagnostic and treatment procedures beyond the scope of primary health care, an emergency outpatient service, or a moderate complexity hospital should be requested by means of referral orders to the RS unit manually or electronically filled out.

- If the health problem is resolved in the health care settings already described above, the patient should be referred back to the primary care unit in order to have his or her possible comorbidities or treatment-related problems treated.

Icteric patients presenting with fever, but with no systemic involvement, can be kept in bed under observation until the final diagnosis. The patient should fast and receive fluid replacement. Antithermic medications may be used if necessary. The patient is submitted to routine clinical exams, such as blood count, total and fractional serum bilirubin levels (conjugated and non-conjugated), aminotransferases (AST and ALT), alkaline phosphatase, prothrombin time, amylase, urinalysis, and abdominal ultrasonography. All these exams can help discriminate between acute hepatitis and pyelonephritis (clinical approach) and mild cholangitis, acute cholecystitis, and acute biliary pancreatitis (clinicalsurgical approach). This differentiation permits the use of antibiotics with gram-negative coverage and anaerobic spectrum in cases of pyelonephritis, cholangitis, and acute cholecystitis. Moreover, these patients can be treated in a moderate complexity hospital or referred to specialised care services for adequate treatment conclusion..$^{11,12,20}$

\section{Scenario IV}

\section{Clinical presentation}

- Painful or painless jaundice with fever, mental confusion, and hypotension associated or not with:

- $\quad$ previous history of biliary pain or biliary surgery

- history of alcohol ingestion or use of hepatotoxic drugs

- $\quad$ signs of hepatopathy (palmar erythema, ascites, gynecomastia, testicular atrophy, vascular spiders, collateral circulation).

- hepatosplenomegaly

Differential Diagnosis

- Severe cholangitis

- Severe acute liver failure (fulminant hepatitis) 
- $\quad$ Severe acute pancreatitis

- Sepsis

\section{Clinical and Regulatory Measures}

- Fasting; hydration and fluid replacement by intravenous peripheral access to restore blood volume

- Oxygen catheter or mask

- Urinary catheter

- Contact with emergency care services (telephone number 192)

- Patient must be removed by an advanced care unit

- Patient must be referred to a tertiary hospital

- Patient must be accommodated for clinical stabilisation or intensive care.

- If the health problem is resolved, the tertiary hospital team should refer the patient back to a primary care unit and describe the treatment performed, including possible complementary treatment. Other comorbidities or treatment problems can be handled by the primary care practitioners, such as surgical wound dressings, mild pain management, and so on.

- Any other complementary diagnostic and treatment procedure beyond primary health care and specialised service should be requested by a referral order to the RS unit manually or electronically filled out.

The referral order for icteric patients presenting with systemic involvement and hemodynamic, respiratory and neurological dysfunctions, with or without fever, can originate from either the primary health care unit or the patient's home. Such cases require initial clinical stabilising measures that can be implemented in both primary care and outpatient emergency units until referral to a tertiary emergency hospital and its intensive care beds. The patient should fast and receive fluid replacement. Antithermic medications may be used if necessary. The patient is submitted to routine clinical exams, such as blood count, total and fractional serum bilirubin levels (conjugated and non-conjugated), aminotransferases (AST and ALT), alkaline phosphatase, prothrombin time, amylase, urinalysis, and abdominal ultrasonography. All these exams can help discriminate fulminant hepatic failure from severe cholangitis, which requires antibiotics with gram-negative coverage and an anaerobic spectrum as well as emergency endoscopic biliary decompression. ${ }^{11,12,20}$

\section{Discussion}

The Brazilian health care reality is quite distant from the academic concepts of the Unified Health System (SUS) assured by laws, policies, rules, and decrees. Hospitals still play a relevant role as health care providers by assuming services which should be provided by primary care units and the regulatory system. According to new concepts, norms, and governmental decrees, primary health care represents the main door for clinical interventions, being expected to co-ordinate the access to all levels of treatment ${ }^{2,4}$, whereas the regulatory system (RS) should organise the access to different points of the health care network depending on the user's health needs. ${ }^{3}$ We are aware not only of the inefficiency of the clinical interventions provided by the primary health care, but also of the negative impact resulting from the excessive demand for outpatient and inpatient services..$^{5,7,21}$

The old health care model is still robust. The clinical coverage provided by the primary health care in Ribeirão Preto is expected to reach approximately $90 \%$ of the population, but only $57.4 \%$ was reached in 2004 . In the same year, the emergency health care represented $30.9 \%$ of the services compared to the expected rate of $15 \%$, whereas specialised care services covered $155 \%$ of the population's health needs. ${ }^{5}$ Within this same scenario, before the advent of the regulatory system in 1999 , only $12.4 \%$ of the patients were admitted to the tertiary emergency university hospital, which was assuming all the functions of the non-inpatient emergency units, more frequently known as first aid care. ${ }^{7}$ This finding reinforces the fact that specialised and emergency care services have been inadequately used. Another finding shows that approximately 55\% of the patients seeking emergency care services could be treated in outpatient units, and $36 \%$ of these cases have not been followed up. ${ }^{21}$ On the other hand, such a lack of efficiency of the health care system does not allow access to primary care services, creating a vicious cycle.

This scenario has contributed to the local decision to amplify and strengthen the primary health care as well as to implement the regulatory system. ${ }^{5}$ Despite the difficulties involved, these tasks have been performed by the Ribeirão Preto Municipal Health Secretary and the RS implementation process has also been discussed. It is expected that the health care services will be integrated by means of a health care network, since none of them has enough resources for solving competently the health problems faced by the population. This health care integration depends on changes in the health care boundaries and professional practices, in addition to co-operation. ${ }^{22}$ Elaboration, validation, and diffusion of the clinical and regulatory protocols involving efforts by primary care practitioners, university professors, and the RS team can contribute to the development of the basis supporting the health care network.

In general, the protocols existing in the literature address only clinical elements and are established to organise specific interventions, such as outpatient, inpatient, and intensive care. Therefore, the challenge resides not only in organising clinical and regulatory interventions through CRPs according to the themes listed earlier, but also in validating these CRPs in co-operation with primary care practitioners and managers in order to assure both integrity and equity.

The development of CRPs requires knowledge of scientific, operational, and administrative processes, consequently being a potential tool for improving the quality of health care and the skills of the professionals involved, in addition to facilitating access to treatment and providing health care guidelines. The treatment of jaundice in adults 
and elderly persons involves different clinical situations ranging from mild to severe forms. Sometimes a delay is observed between the onset of symptoms and the clinical investigation/treatment, but there are cases that could be routinely evaluated instead of being referred to tertiary investigation. It is not uncommon to see patients with jaundice, but presenting no pain or fever, being submitted to CT investigation in a tertiary emergency hospital. On the other hand, there are patients with severe cholangitis who have difficulties in obtaining access to a tertiary emergency hospital, as well as cases of neoplasia whose treatment begins months after the onset of cholestasis symptoms. In the majority of cases of obstructive jaundice, the primary care team diagnoses the patient as having hepatitis and refers the case to specialised care before performing an adequate clinical evaluation and routine laboratory exams. At this level, the clinical evaluation is restarted and new routine exams are ordered, including unnecessary and even invasive ones, such as an endoscopic retrograde cholangiography with biliary drainage. ${ }^{23}$ Image exams like computer tomography may also be ordered, although such a procedure is likely to be performed again due to the quality of, or the time elapsed between the exam and the next clinical evaluation.

The disequilibrium between clinical and social conditions regarding some patients and the inability to carry out the clinical evaluations, exams, and procedures imposed by a fragmented health care system, which lacks coordination and organisation, result in generalised dissatisfaction, treatment delay, and resource waste. Definition of primary care entry door, organised and regulated health care services, the possibility of professional practice changes, and co-operation for elaborating and validating the CRPs can, indeed, make health care more rational and humane despite the different opinions of some authors ${ }^{24}$.

\section{Conclusion}

By implementing these CRPs, it is expected that the access to the health care system can be optimised and extended, including reduction of the opportunities lost at the user-system interface and development of a more cooperative health care network where the user's and practitioner's aspirations do not overcome the patient's health needs.

\section{References}

1. BRASIL. Lei n ${ }^{\circ} 8142 / 90$, de 28 de dezembro de 1990. Dispõe sobre as condições para a promoção, proteção e recuperação da saúde, a organização e o funcionamento dos serviços correspondentes e dá outras providências. Brasília, 28 de dez 1990b. www.pessoalsus.inf.br/ Normas/Lei\%208142 90.htm.

2. Starfield, B. Primary care: concept, evaluation and policy. New York, Oxford, University Press, 1992.

3. BRASIL. Ministério da Saúde. Portaria no 399 de 22 de fevereiro de 2006. Divulga o Pacto pela Saúde 2006 - consolidação do SUS e aprova as diretrizes operacionais do referido Pacto. Diário Oficial da União, Brasília, 2006.

4. BRASIL. Ministério da Saúde. Portaria no 648 de 28 de março de 2006. Institui a Política Nacional de Atenção Básica. Diário Oficial da União, Brasília, DF, mar.2006.

5. Ribeirão Preto, Plano Municipal de Saúde, 2005-2008, 2005 Disponível em: $<$ http://www.saude.ribeiraopreto.gov.br .

6. BRASIL. Ministério da Saúde. Portaria no 1101/GM, de 12 de junho de 2002. Dispõe sobre os parâmetros de cobertura assistencial no âmbito do SUS. Brasília, 2002.

7. Santos JS, Scarpelini S, Brasileiro SLL, Ferraz CA, Dalloro MELV, Sá MFS. Avaliação do Modelo de Organização da Unidade de Emergência do HCFMRP-USP, Adotado como Referência, as Políticas Nacionais de Atenção às Urgências e de Humanização. Medicina, Ribeirão Preto SP.2003;36:498-515.

8. WHO. Guidelines for Who Guidelines 23 pg, 2003

9. Freelove R, Walling AD. Pancreatic cancer: diagnosis and management. American Family Physician. 2006;73:485-92.

10. O'Connor KW, Snodgrass PJ, Swonder JE. A blinded prospective study comparing four current noninvasive approaches in the differential diagnosis of medical versus surgical jaundice. Gastroenterology. 1983;84:1498.

11. Wada K, Takada T, Kawarada Y, Nimura Y, Miura F, Yoshida M, Mayumi T, Strasberg S, Pitt HA, Gadacz TR, Büchlers MW, Belghit J, Santibanes E, Gouma DJ, Neuhaus H, Dervenis C, Fan ST, Chen MF, Ker1 CG, Bornman PC, Hilvano SC, Kim SW, Liau KH, Kim MH. Diagnostic criteria and severity assessment of acute cholangitis: Tokyo guidelines. J Hepatobiliary Pancret Surg. 2007;14:52-8.

12. Miura I, Takada T, Kawarada Y, Nimura Y, Wada K, Hirota M, Nagino M, Tsuyuguchi T, Mayumi T, Yoshida M, Strasberg SM, Pitt HA, Belghiti J, Santibanes E, Gadacz TR, Gouma DJ, Fan ST, Chen MF, Padbury RT, Bornman PC, Kim SW, Liau LH, Belli G, Dervenis C. Flowcharts for the diagnosis and treatment of acute cholangitis and cholecystitis: Tokyo guidelines. J Hepatobiliary Pancret Surg. 2007;14:27-34..

13. Lidofsky SD, Kobos R. Jaundice. In: Sleisenger and Fordtrant's Gastrointestinal and Liver Disease. 8ed. Philadelphia: Saunders Elsevier; 2006. p 301-16.

14. Beckingham IJ, Ryder SD. ABC of diseases of the liver, pancreas and biliary system: investigation of liver and biliary disease. BMJ. 2001;322:33-6.

15. Ryder SD, Beckingham IJ. ABC of diseases of the liver, pancreas and biliary system: other causes of parenchymal liver disease. BMJ. 2001;322:290-2.

16. Roche SP, Kobos R: Jaundice in the adult patient. Am Fam Physician. 2004;69:299-304.

17. Merriman RB, Peters MG. Approach to the patient with jaundice. In: Yamada T Textbook of Gastroenterology. 4ed.Philadelphia: Lippincott Williams and Wilkins; 2003. p 911-28.

18. Bergasa NV. Medical palliation of the jaundiced patient with pruritus. Gastroenterol Clin N Am. 2006;35:113-23. 
19. Giannini EG, Testa R, Savarino V. Liver enzyme alteration: a guide for clinicians. CMAJ. 2005;172:36779 .

20. Takeda K, Takada T, Kawarada Y, Hirata K, Mayumi T, Yoshida M, Sekimoto M, Hirota M, Kimura Y, Isaji S, Koizumi M, Otsuki M Matsuno S. JPN guidelines for the management of acute pancreatitis: medical management of acute pancreatitis. J Hepatobiliary Pancret Surg. 2006;13:42-7.

21. Lovalho AF. Administração de serviços de saúde em urgências e emergências. O mundo da saúde, São Paulo. 2004;28:160-71.
22. Hartz ZMA, Contandriopolus AP. Integralidade da atenção e integração dos serviços de saúde: desafios para avaliar a implantação de "um sistema sem muros". Cad. Saúde Pública. 2004;20:5331-6.

23. Santos JS, Salgado Jr W, Módena JLP, Brunaldi JE, Ceneviva R. Effect of preoperative endoscopic decompression on malignant biliary obstruction and postoperative infection. Hepato-Gastroenterology. 2005;52:45-7.

24. Puccini PT, Cecilio LCO. A humanização dos serviços e o direito à saúde. Cad. Saúde Pública, 2004;20:134253.

\section{Correspondence:}

José Sebastião dos Santos

Department of Surgery and Anatomy

Ribeirão Preto Faculty of Medicine, University of São Paulo

Av. Bandeirantes 3900

No conflict of interest

14048-900 Ribeirão Preto, SP, Brazil

jsdsanto@fmrp.usp.br

\section{How to cite the article:}

Santos JS, Kemp R, Sankarankutty AK, Salgado Jr W, Souza FF, Teixeira, AC, Rosa GV, Castro-e-Silva O. Clinical and regulatory protocol for the treatment of jaundice in adults and elderly subjects: A support for the health care network and regulatory system. Acta Cir Bras [serial on the Internet], 2008; 23 Suppl 1. Available from URL: http://www.scielo.br/acb.

\section{Comments:}

This is a timely publication and one out of few papers to underline the importance of surgical protocols in a health regulatory system. The authors describe a scientific collaboration between university and health care system in order to elaborate clinical and surgical protocols. The goal of the study is to minimize the imbalance between patient's needs and treatment options. An extensive protocol for jaundice in adults and elderly is presented considering clinical features, diagnosis hypothesis, and regulatory measures. The authors expect that the access to health care system can be optimized in a more co-operative way between patients and the health system. I expect that data obtained with its implantation will be published in a near future.

\section{Carlos Gilberto Carlotti Jr.}

$\mathrm{PhD}$, Associate Professor, Division of Neurosurgery, Department of Surgery and Anatomy, - Ribeirão Preto Faculty of Medicine, University of São Paulo, Brazil. 